\title{
Study of left ventricular diastolic dysfunction in recently diagnosed hypertensives in Central Nepal
}

\author{
Shankar Laudari, Sachin Dhungel, Pradip Jung KC, Guru Prasad, Rabindra Bhattacharya, G \\ Subramanyam \\ Department of Cardiology, College of Medical Sciences, Bharatpur, Nepal
}

\section{Correspondence \\ Dr Shankar Laudari \\ Department of Cardiology, \\ College of Medical Sciences, \\ Bharatpur, Nepal \\ Email: 1shankar2@hotmail.com}

DOI: http://dx.doi.org/10.3126/ jcmsn.v12i1.14682

\begin{abstract}
Background \& Objectives: Left ventricular diastolic dysfunction is now well established as a cause of left sided heart failure and as a powerful predictor of cardiovascular events. It is attributed mostly to systemic hypertension. The objective of the study was to determine the prevalence of left ventricular diastolic dysfunction in recently diagnosed hypertensives in Nepalese population using echocardiography. Materials \& Methods: Two-dimensional echocardiography was performed on 120 newly diagnosed patients of systemic hypertension. Transmitral Doppler indexes of diastolic function, Valsalva maneuver applied to the same mitral inflow pattern, pulsed tissue Doppler of the mitral annulus, deceleration time, isovolumic relaxation time and pulmonary venous flow patternwere assessed. Results: The age of the patients in our study ranged from 20 to 84 years with mean age of 50years \pm 14.13 years (standard deviation) and male:female ratio being 1.35:1. Hypertensive patients were highest in age group 45-64 years followed by 25-44 years in both the genders. Majority of the patients had stage 1 hypertension $(44.16 \%)$ followed by stage 2 HTN in $34.17 \%$ and pre-hypertension in $21.67 \%$. The majority of the patients in our study had Grade 1 LVDD $(66.67 \%), 10.83 \%$ patients had Grade II LVDD, only $2.50 \%$ had non-restrictive Grade III LVDD and none had LVDD-IV. Stage II hypertensives had more LVDD(I+II+III): 39/41$95.12 \%$ than stage I hypertensives(39/53-73.58\%) and pre-hypertensives $(8 / 26-30.77 \%)$. The association between stages of systemic HTN and LVDD was found to be highly statistically significant $(p=0.002)$. Conclusion: Our study showed that left ventricular diastolic dysfunction is a common entity in Nepalese population with systemic hypertension.

Key words: Diastolic dysfunction; Nepalese population; Systemic hypertension
\end{abstract}

Citation: Laudari S, Dhungel S, KC PJ, Prasad G, Bhattacharya R, Subramanyam G. Study of left ventricular diastolic dysfunction in recently diagnosed hypertensives in Central Nepal. JCMS Nepal. 2016;12 (1):14-8.

\section{INTRODUCTION}

Hypertension remains the most common, readily identifiable and reversible risk factor for myocardial infarction, stroke, heart failure, atrial fibrillation, aortic dissection and peripheral arterial disease. The global burden of hypertension is rising and projected to affect 1.5 billion persons by the year 2025 which is one third of the world's population. ${ }^{1}$

Diastolic dysfunction is now well established as a cause of left sided heart failure and as a powerful predictor of cardiovascular events. Diastolic dysfunction is present in over $25 \%$ of adults over 40 years of age and accounts for approximately $50 \%$ of heart failure cases. ${ }^{2}$
Systemic hypertension (HTN) is the most commonly associated condition in patients with left ventricular diastolic dysfunction (LVDD).

\section{MATERIALS AND METHODS}

This is a hospital based observational crosssectional study over a period of 18 months from July 2012 to January 2014.

\section{Inclusion criteria}

All the consecutive hypertensive patients attending cardiology outpatients department (OPD), ward and coronary care unit (CCU) were included in the study.

\section{Exclusion}

Patients with coronary artery disease, arrhythmia 
Table 1: Age and sex distribution

\begin{tabular}{ccccccc} 
Age & \multicolumn{2}{c}{ Male } & \multicolumn{2}{c}{ Female } & \multicolumn{2}{c}{ Total } \\
(years) & No. & $\%$ & No. & $\%$ & No. & $\%$ \\
\hline$<25$ & 6 & 5.00 & 0 & 0.00 & 6 & 5.00 \\
\hline $25-44$ & 25 & 20.83 & 16 & 13.33 & 41 & 34.17 \\
\hline $45-64$ & 26 & 21.67 & 27 & 22.50 & 53 & 44.17 \\
\hline & 12 & 10.00 & 8 & 6.67 & 20 & 16.67 \\
\hline Total & & 69 & & 51 & & \\
\hline
\end{tabular}

Table 2: Classification of systemic HTN

\begin{tabular}{|lcccc|}
\multicolumn{1}{c}{ Parameter } & $\begin{array}{c}\text { No. of } \\
\text { patie } \\
\text { nts }\end{array}$ & $\begin{array}{c}\text { Sex } \\
\text { Ma } \\
\text { le }\end{array}$ & $\begin{array}{c}\text { Fem } \\
\text { ale }\end{array}$ & $\begin{array}{c}\text { Percent } \\
\text { age }\end{array}$ \\
\hline Isolated systolic HTN & 11 & 4 & 7 & $9.17 \%$ \\
\hline Isolated diastolic HTN & 9 & 5 & 4 & $7.50 \%$ \\
\hline Accelerated HTN & 19 & 7 & 12 & $15.83 \%$ \\
\hline Hypertensive crisis & 10 & 7 & 3 & $8.33 \%$ \\
\hline -Hypertensive urgency & 4 & 3 & 1 & $3.33 \%$ \\
\hline $\begin{array}{l}\text {-Hypertensive } \\
\text { emergency }\end{array}$ & 6 & 4 & 2 & $5.00 \%$ \\
\hline
\end{tabular}

(eg. atrial fibrillation), obesity, diabetes mellitus, renal dysfunction (creatinine clearance $<90 \mathrm{ml} /$ hour), sleep apnoea, hypertrophic cardiomyopathy, valvular heart disease and constrictive pericarditis were excluded from the study. .

A verbal consent was taken from the patient for the data collection regarding systemic hypertension, performing transthoracic echocardiography (2D) for assessing LV diastolic function.

\section{Data collection}

Data collection was done as per predefined and tested structured proforma. The datas were regularly entered and analyzed in SPSS software. A total of recently detected 120 hypertensive patients were included in the study.

\section{Statistical analysis}

For descriptive data ratio, mean and standard deviation were calculated and for qualitative data like the possible association between risk factor and development of LVDD will be tested using chi square and students paired $\mathrm{t}$ test as applicable. Univariate and multivariate logistic regression analysis were done to evaluate the association of HTN and/or multiple risk factors to that of LVDD.

Ethical clearance was obtained from the Institutional review board of College of Medical Sciences-Bharatpur, Chitwan, Nepal.

\section{RESULTS}

\section{Characteristics of the Subjects}

The age of the patients in our study ranged from 20 to 84 years with mean age of 5oyears \pm 14.13 years (standard deviation). Females constituted 51 in number $(42.5 \%)$ whereas males were 69 (57.5\%) with male:female ratio being 1.35:1. Majority of the patients $(44.17 \%)$ in this study belonged to 45 64 years of age followed by $25-44$ years $(34.17 \%)$ and the least among less than 25 years $(5.00 \%)$. The age-wise distribution of the patients with gender is illustrated in the Table1.

Out of the total hypertensives, accelerated HTN was recorded in $15.83 \%$ patients, isolated systolic HTN in $9.17 \%$, isolated diastolic HTN in $7.50 \%$ and hypertensive crisis in $6.67 \%$ as shown below in the Table 2.

In this study, the majority of the patients(40 in number:33.33\%) were clinically asymptomatic. 37 patients $(30.83 \%)$ presented with mild headache and dizziness, 13 patients $(10.83 \%)$ had palpitation and 12 patients(10\%) had mild atypical chest pain with exertional shortness of breath, NYHA-Class II.

The following table shows the various assessment parameters of LVDD observed in our study. The value depicted below in Table 3 is the average

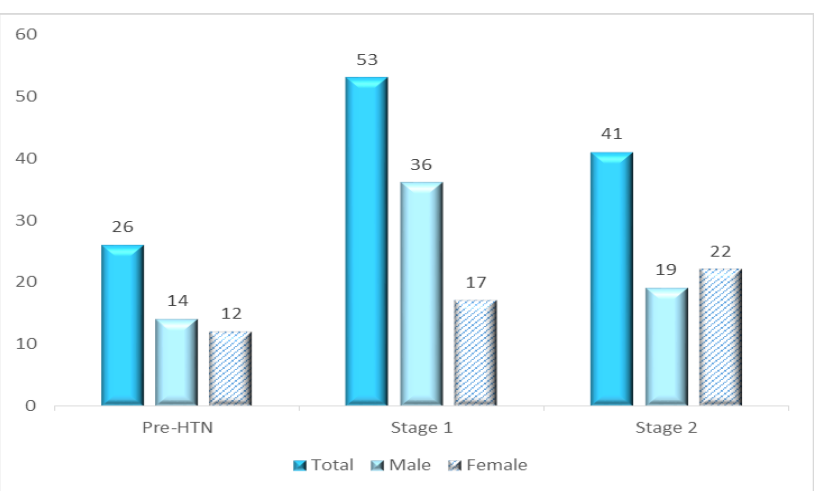

Fig 1: Stages of systemic HTN and sex distribution

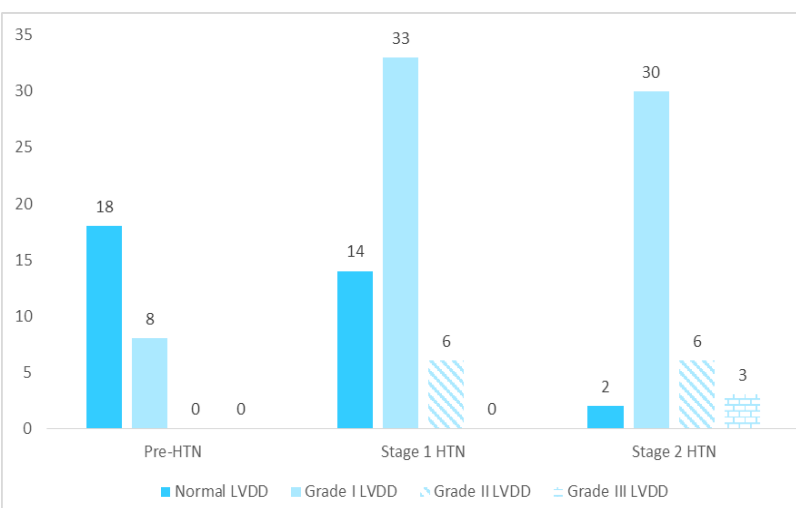

Fig 2: Relation of stages of systemic HTN with grades of LVDD 
Table 3: Echocardiographic assessment parameters of LV Diastolic Function

\begin{tabular}{|c|c|c|c|}
\hline Parameter & Among hypertensives & Among normal & P value \\
\hline Peak mitral E (m.s-1) & $0.65(0.40-0.90)$ & $0.7(0.5-0.9)$ & $<0.05$ \\
\hline Peak mitral A (m.s-1) & $0.86(0.41-0.91)$ & $0.6(0.4-0.9)$ & $<0.05$ \\
\hline $\mathrm{E} / \mathrm{A}$ ratio & $0.88(0.42-2.50)$ & $1.2(0.7-1.8)$ & $<0.05$ \\
\hline \multicolumn{4}{|l|}{ TDI,mitral annulus } \\
\hline \multicolumn{4}{|l|}{ Septal } \\
\hline$-\mathrm{e}^{\prime}, \mathrm{m} / \mathrm{sec}$ & $0.07(0.04-0.11)$ & $0.09(0.05-0.12)$ & 0.05 \\
\hline$-\mathrm{a}^{\prime}, \mathrm{m} / \mathrm{sec}$ & $0.11(0.07-0.14)$ & $0.11(0.08-0.15)$ & 0.12 \\
\hline$-E / e^{\prime}$ & $5.10(3.88-14.20)$ & $7.78(4.62-13.33)$ & $<0.01$ \\
\hline \multicolumn{4}{|l|}{ Lateral } \\
\hline$-e^{\prime}, \mathrm{m} / \mathrm{sec}$ & $0.08(0.06-0.16)$ & $0.11(0.07-0.15)$ & $<0.05$ \\
\hline$-\mathrm{a}^{\prime}, \mathrm{m} / \mathrm{sec}$ & $0.13(0.07-0.17)$ & $0.11(0.08-0.16)$ & 0.06 \\
\hline$-E / e^{\prime}$ & $5.60(4.33-15.10)$ & $6.00(3.85-10.00)$ & $<0.05$ \\
\hline \multicolumn{4}{|l|}{ Valsalva maneuver } \\
\hline$-\mathrm{VS} \mathrm{E} / \mathrm{A}$ & $1.12(0.67-1.4)$ & $0.80(0.44-1.3)$ & 0.06 \\
\hline$-\Delta \mathrm{E} / \mathrm{A}$ & $0.42(0-1.2)$ & $0.37(0-1.0)$ & 0.09 \\
\hline Deceleration time (msec) & $230(155-254)$ & $190(160-240)$ & 0.05 \\
\hline IVRT (msec) & $84(64-105)$ & $74(60-88)$ & 0.05 \\
\hline \multicolumn{4}{|l|}{ Pulmonary vein flow } \\
\hline -Peak PV systolic velocity(S) (m.s-1) & $0.61(0.41-0.85)$ & $0.60(0.40-0.80)$ & 0.14 \\
\hline -Peak PV diastolic velocity(D) (m.s-1) & $0.43(0.31-0.76)$ & $0.40(0.30-0.60)$ & 0.12 \\
\hline Pulmonary S/D & $1.30(0.67-2.12)$ & $1.40(1.00-2.00)$ & 0.07 \\
\hline Peak PV reverse flow velocity AR (m.s-1) & $115(95-180)$ & $123(105-157)$ & $<0.05$ \\
\hline
\end{tabular}

(mean) in total 120 patients. But, each individual was assessed in detail with the following parameters.

It was noticed that mean E/A ratio was $0.88 \pm 0.29$ $(0.42-2.5)$ in the overall hypertensives compared to $1.2(0.7-1.8)$ in the normal population. Similarly, Septal E/e' ratio was 5.10(3.88-14.20) and Lateral E/e' was 5.60(4.33-15.10) among the study group whereas normal population had Septal and Lateral E/e' 7.78(4.62-13.33) and 6.00(3.85-10.00) respectively.

Based on those above parameters, LV diastolic function was assessed and categorized into Normal, Grade I, Grade II, Grade III and Grade IV.

The majority of the patients in our study had Grade 1 LVDD (66.67\%) or mild impaired relaxation. $10.83 \%$ patients had Grade II LVDD, only $2.50 \%$ had non-restrictive Grade III LVDD and none had LVDD-IV. It was concluded that the incidence of LVDD(I+II+III) was $80 \%$ in our study population whereas combined LVDD II+III contributed to only $13.33 \%$ of the sample size. The $p$ value for $L V$ diastolic function and sex distribution is 0.175
$(>0.05)$ which suggests no statistical significance association.

LVDD and age distribution:

The association between the stages of systemic HTN and the severity of diastolic dysfunction was assessed as shown in Fig 2. Out of 120 patients, 93 $(77.50 \%)$ were found to have left ventricular diastolic dysfunction. It was noticed that Stage II hypertensives had more LVDD(I+II+III): 39/41$95.12 \%$ than stage I hypertensives (39/53-73.58\%) and pre-hypertensives (8/26-30.77\%).

Mild ventricular impaired relaxation was the most common finding in all hypertensive groups $(8 / 26-$ $30.77 \%$ in pre-HTN, $33 / 53-62.26 \%$ in stage I HTN and $30 / 41-73.17 \%$ in stage II HTN). The association between stages of systemic HTN and LVDD was found to be highly statistically significant $(p=0.002)$. Concentric LVH was detected in $22(18.33 \%)$ patients in our study.

\section{DISCUSSION}

A total of 120 patients were included in our study, the age ranging from 20 to 84 years with mean age 


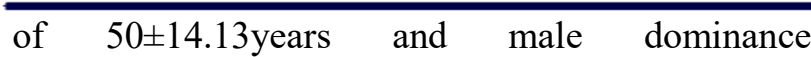
$(\mathrm{M}: \mathrm{F}=1.35: 1)$. In a study in Nigeria (2005) by Adewole et $\mathrm{al}^{3}, 98$ patients were included with female dominance (M:F=0.88:1). Masliza M, Daud SM and Khalid $\mathrm{Y}^{4}$ (2005) included 396 subjects (198 newly diagnosed hypertensives age and gender matched and 198 normotensives with age ranging from 30 to 50 years.

The majority of the patients in our study had Grade $1 \operatorname{LVDD}(66.67 \%)$ or mild impaired relaxation. $10.83 \%$ patients had Grade II LVDD, only $2.50 \%$ had non-restrictive Grade III LVDD and none had LVDD-IV. In a similar study by Masliza, Daud and Khalid4 including 396 subjects, patients with newly diagnosed hypertensives (NDHT) had reduced E/A ratio and shortened deceleration time. The peak A velocity and isovolumetric relaxation time (IVRT) were increased in the newly diagnosed hypertensive (NDHT) group. The prevalence of diastolic dysfunction was increased in the NDHT group, $18.6 \%$ vs $3.4 \%, \mathrm{P}<0.001$. Of the 32 NDHT subjects who had diastolic dysfunction, $84.4 \%$ (27) had no left ventricular hypertrophy (LVH) and $15.7 \%$ (5) had LVH.

In a study from India by Mukesh Laddha, Vishal Sachdeva, PM Diggikar, PK Satpathy and AL Kakrani $^{5}$ (2014), diastolic dysfunction (assessed by E/A ratio) was present in $61.4 \%$ of patients.

In the Hypertension Genetic Epidemiology Network (Hyper GEN) study6, 515 males and 839 females, mostly treated (95\%) hypertensive participants were enrolled. Mitral E-wave and Awave velocities $(p<0.001)$ were lower in men than in women, but the mitral E/A ratio and atrial filling fraction were nearly identical in both genders. Deceleration time (p-0.018) and isovolumic relaxation time (IVRT) were longer in men than in women $(\mathrm{p}<0.001)$. Prolonged IVRT was present in more men than women $(14 \%$ vs $7 \%, p<0.05)$.

The overall prevalence of diastolic abnormalities, as defined by the European Study Group7 on Diastolic Heart Failure i.e. age dependent isovolumic relaxation time (92-105 ms) and early (E-wave) and late (A-wave) left ventricular filling (E/A-ratio, 1$0.5)$ was $11.1 \%$. The prevalence of diastolic abnormalities varied according to age: from $2.8 \%$ in individuals aged $25-35$ years to $15.8 \%$ among those older than 65 years $(\mathrm{P}<0.01)$. Significantly higher rates of diastolic abnormalities were observed in men as compared to women $(13.8 \%$ vs $8.6 \%$, $\mathrm{P}<0.01)$. Independent predictors of diastolic abnormalities were arterial hypertension, evidence of left ventricular (LV) hypertrophy and coronary artery disease.

It was noticed that Stage II hypertensives had more LVDD(I+II+III): $39 / 41-95.12 \%$ than stage I hypertensives(39/53-73.58\%) and pre-hypertensives $(8 / 26-30.77 \%)$ which was found to be statistically significant $(\mathrm{p}<0.05)$.

GU Adamu, AI Katibi, and AM Araoye ${ }^{8}$ from Nigeria (2010) studied one hundred and fifty newly diagnosed cases of systemic HTN aged between 35 years and 74 years between 2005 and 2006. They reported the prevalence of LV diastolic dysfunction in the newly diagnosed hypertensives and normotensives controls $62 \%$ and $11.3 \%$ respectively. The commonest type of diastolic dysfunction noted in the study, both in the systemic hypertensives and normotensives was the impaired relaxation pattern, $84.9 \%$ and $8.7 \%$ respectively. Also there was positive correlation between stages of systemic hypertension and LVDD severity.

Recent studies in Asia on the prevalence of DD by Masliza et $\mathrm{al}^{4}$ found a lower incidence of $18.6 \%$ (32 out of 198) in their newly diagnosed with systemic hypertensives and six (3.4\%) among the controls.

The study by Snider et $\mathrm{al}^{9}$ in children with systemic hypertension emphasized the presence of diastolic dysfunction even in the absence of LVH.

In the Olmsted County Heart Function Study10, a cohort of 2042 persons 45 years or older had been evaluated for diastolic function (examination 1:1997-2000) and same group were re-evaluated in examination two (2001-2004). The cohort was followed passively and incident heart failure events ascertained (2004-2010). During the four years between examinations one and two, diastolic dysfunction prevalence increased from $23.8 \%$ to $39.2 \% \quad(\mathrm{P}<0.001)$. Diastolic function grade worsened in $23.4 \%$ of participants, was unchanged in $67.8 \%$ and improved in $8.8 \%$. Worsened diastolic dysfunction was associated with age 65 years or older.

Inflammation has been proposed to be a common pathway through which conditions like HTN and DM lead to ventricular stiffness and DD and eventually to decompensated heart failure. ${ }^{11}$

The data presented, thus far, offers compelling evidence to support an association between inflammation and hypertension. However, there is accumulating data from the current medical literature to suggest that it is not only blood pressure reduction per se but the way in which 
blood pressure is lowered that is most important factor in hypertension treatment. ${ }^{12}$

\section{CONCLUSION}

This study highlights the fact that left ventricular diastolic dysfunction is common in Nepalese population with systemic hypertension. These patients need to be properly treated with antihypertensive medications to prevent from heart failure with normal ejection fraction.

\section{Conflict of interest}

The authors do not have any conflict of interest in publication of this article and do not have any financial disclosure.

\section{REFERENCES}

1. Ronald G. Victor. Systemic Hypertension: Mechanisms and Diagnosis. By Robert O Bonow, Douglas L Mann, Douglas P Zipes, Peter Libby, Eugene Braunwald ed. In Braunwald's Heart Disease:A Textbook of Cardiovascular Medicine, 9th ed. Philadelphia: Elsevier Saunders 2012;45:935-53.

2. William F Armstrong and Thomas Ryan. Evaluation of left ventricular diastolic function. In Feigenbaum's Echocardiography, 7th edition, Philadelphia, Lippincott Williams and Wilkins 2005;7:159-83.

3. Adewole A, Akinyemi Aje, Okechukwu S, Dike B, Olulola 0. Oladapo, Ayodele Falase: Left Ventricular Diastolic Function Parameters in Hypertensives. Nati Med Assoc. 2005;97:41-5.

4. Masliza M, Daud SM, Khalid Y. Assessment of diastolic function in newly diagnosed hypertensives. Ann Acad Med Singapore 2005;34:684-5.

5. Mukesh Laddha, Vishal Sachdeva, PM Diggikar, PK Satpathy, AL Kakrani. Echocardiographic assessment of cardiac dysfunction in patients of end stage renal disease on hemodialysis. JAPI 2014;62:28-32.

6. Bella JN, Palmieri V, Kitzman DW, Liu JE, Oberman A, Hunt SC et al. Gender difference in diastolic function in hypertension (the Hyper GEN study) in Am J Cardiol 2002;89:1052-6.

7. Kingue S, Mbango GF, Ouankou M. Echocardiographic study of left ventricular hypertrophy in 98 black hypertensives. Trop Cardiol 1993; 19: 51-5.

8. GU Adamu, AI Katibi, George O Opadijo, ABO Omotoso, AM Araoye. Prevalence of left ventricular diastolic dysfunction in newly diagnosed Nigerians with systemic hypertension: a pulsed wave Doppler echocardiographic study. Afr Health Sci 2010; 10: 177-82.

9. Snider AR, Gidding SS, Rocchini AP, Rosenthal A, McDonald D, Crowlly DC et al. Doppler evaluation of left ventricular diastolic filling in children with systemic hypertension. Am J Cardiol 1985; 56:921-6.

10. Abhayaratna WP, Marwick TH, Smith WT, Becker NG. Characteristics of left ventricular diastolic dysfunction in the community: an echocardiographic survey. Heart 2006; 92:1259-64.

11. Ogata T, Miyauchi T, Sakai S, Takanashi M, IrukayamaTomobe Y, Yamaguchi I. Myocardial fibrosis and diastolic dysfunction in deoxycorticosterone acetate-salt hypertensive rats is ameliorated by the peroxisome proliferator-activated receptor-alpha activator fenofibrate, partly by suppressing inflammatory responses associated with the nuclear factor-kappa-B pathway. J Am Coll Cardiol 2004;43:1481-8.
12. Boos CJ, Lip GYH. Elevated high-sensitivity C-reactive protein, large arterial stiffness and atherosclerosis: a relationship between inflammation and hypertension? J Human Hypertens 2005;19:511-3. 